Case Report

\title{
Simultaneous Manifestation of Chronic Myelomonocytic Leukemia and Multiple Myeloma during Treatment by Prednisolone and Eltrombopag for Immune-Mediated Thrombocytopenic Purpura
}

\author{
Masao Hagihara, Morihiro Inoue, Kenichiro Kodama, Tomoyuki Uchida, and Jian Hua \\ Department of Hematology, Eiju General Hospital, 2-23-16 Higashi-Ueno, Taito-ku, Tokyo 110-8645, Japan \\ Correspondence should be addressed to Masao Hagihara; hagihara@eijuhp.com
}

Received 30 March 2016; Revised 9 June 2016; Accepted 10 July 2016

Academic Editor: Kazunori Nakase

Copyright (c) 2016 Masao Hagihara et al. This is an open access article distributed under the Creative Commons Attribution License, which permits unrestricted use, distribution, and reproduction in any medium, provided the original work is properly cited.

An 80-year-old man was admitted to our hospital because of severe thrombocytopenia. He was diagnosed with idiopathic thrombocytopenia, and prednisolone together with eltrombopag was started, leading to significant improvement of platelet counts. Four years later, there was a prominent increase of peripheral blood monocytes, which was accompanied by recurrence of thrombocytopenia. Bone marrow aspirates and serum electrophoresis revealed coexistence of chronic myelomonocytic leukemia (CMML) and multiple myeloma (MM). The patient received lenalidomide plus dexamethasone therapy but died due to exacerbation of the disorder. It was supposed that thrombocytopenia was secondarily caused by CMML and MM developed at a later period.

\section{Introduction}

Immune-mediated thrombocytopenic purpura (ITP) is a disorder which occurs spontaneously as idiopathic thrombocytopenic purpura or develops secondarily from various disorders, such as infection or malignancies through mechanisms of immune alteration [1]. Myelodysplastic syndrome (MDS) is one such underlying disorder that manifests isolated thrombocytopenia, although the incidence is quite low [2]. Chronic myelomonocytic leukemia (CMML) overlaps pathophysiologically with MDS and is categorized as MDS/MPN (myeloproliferative neoplasm) in the WHO 2008 classification.

Patients with multiple myeloma (MM) or monoclonal gammopathy of undetermined significance (MGUS) have a significantly high risk of developing MDS, CMML, or acute myeloid leukemia (AML) compared with healthy controls. Furthermore, there have been several case reports that demonstrated the simultaneous occurrence of MM/MGUS and myeloid malignancy. In contrast, there has been no report of MDS or CMML preceding the development of MM.
In the present case, it was concluded that CMML likely existed as an underlying disorder for the development of ITP, which had been in remission under successful treatment with eltrombopag, a recombinant thrombopoietin receptor (TPO$\mathrm{R})$. Four years later, CMML exacerbated simultaneously with the appearance of MM.

\section{Case Report}

An 80-year-old man was referred to our hospital because of severe thrombocytopenia (Table 1). Bone marrow (BM) study showed an increased number of megakaryocytes. Neither significant increase of monocytes nor plasma cells were observed. As dysplastic change was not evident, he was diagnosed with ITP. At admission, prednisolone was started at $0.5 \mathrm{mg} / \mathrm{kg}$, which did not result in significant improvement of platelet counts $\left(1.7 \times 10^{4} / \mathrm{mm}^{3}\right.$ to $\left.2.3 \times 10^{4} / \mathrm{mm}^{3}\right)$ for 1 month, and eltrombopag was added at $12.5 \mathrm{mg} / \mathrm{day}$ as a starting dose and then gradually increased to $37.5 \mathrm{mg} /$ day during 4 months. Platelet counts continued to be stable (at around $10 \times 10^{4} / \mathrm{mm}^{3}$ ) through this treatment (Table 2). Four years 


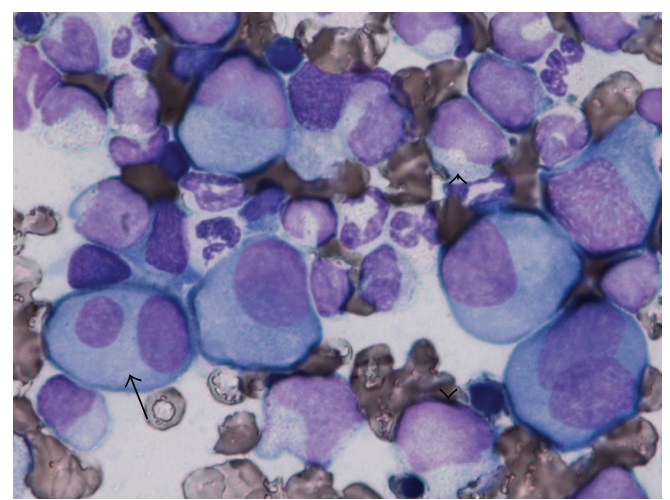

(a)

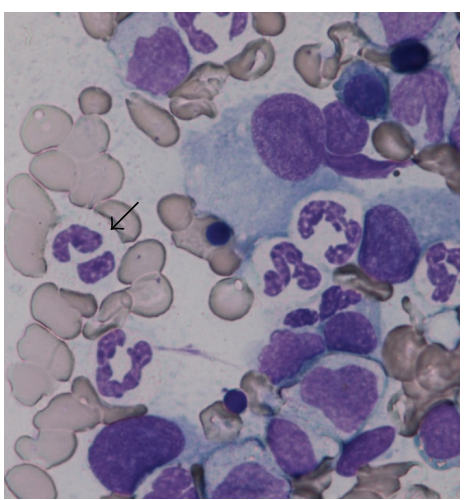

(b)

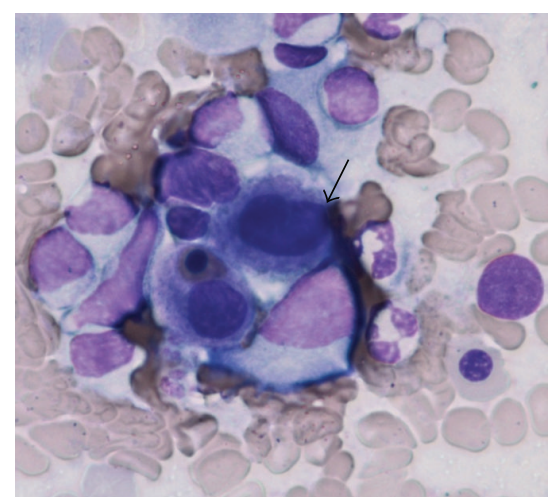

(c)

FIGURE 1: Bone marrow aspirate on second admission (Giemsa staining). A significant increase of monocytes (arrowhead) as well as plasma cells (arrow) was observed in bone marrow aspirates ( $(\mathrm{a}), \times 400$ in magnification). Myelodysplastic change was also detected, showing as hypogranulated neutrocytes with Pseudo-Pelger nuclei ((b), ×1000 in magnification) or micromegakaryocytes ((c), ×1000 in magnification).

TABLE 1: Laboratory data on first admission.

\begin{tabular}{lc}
\hline WBC & $3800 / \mathrm{mm}^{3}$ \\
$\quad$ Band + seg & $15.5 \%$ \\
$\quad$ Baso & $0.5 \%$ \\
$\quad$ Eosino & $0 \%$ \\
$\quad$ Mono & $28 \%$ \\
$\quad$ Lymph & $26 \%$ \\
RBC & $439 \times 10^{6} / \mathrm{mm}^{3}$ \\
Hb & $13.3 \mathrm{~g} / \mathrm{dL}$ \\
MCV & 92.7 \\
MCH & 30.3 \\
Platelets & $3.6 \times 10^{4} / \mathrm{mm}^{3}$ \\
TP & $7.1 \mathrm{~g} / \mathrm{dL}$ \\
BUN & $13.5 \mathrm{mg} / \mathrm{dL}$ \\
Cr & $0.89 \mathrm{mg} / \mathrm{dL}$ \\
Na & $140 \mathrm{mEq} / \mathrm{L}$ \\
K & $4.7 \mathrm{mEq} / \mathrm{L}$ \\
AST & $17 \mathrm{U} / \mathrm{L}$ \\
ALT & $12 \mathrm{U} / \mathrm{L}$ \\
LDH & $114 \mathrm{U} / \mathrm{L}$ \\
IgG & $1729 \mathrm{mg} / \mathrm{dL}$ \\
IgA & $404 \mathrm{mg} / \mathrm{dL}$ \\
IgM & $46 \mathrm{mg} / \mathrm{dL}$ \\
PAIgG & $118 \mathrm{ng} / 10^{7} \mathrm{cells}$ \\
\hline
\end{tabular}

PAIgG: platelet-agglutinated IgG.

later, there was an increase of peripheral blood monocytes, which was then accompanied by decreased platelet counts and severe anemia (Table 3). At this period, bone marrow examination was again performed and revealed a significant increase in monocytes as well as plasma cells (Figure 1), as determined based on the $\kappa$ chain expression on CD38 gating by flow cytometry (Figure 2). Peripheral blood (PB) monocytes exceeded $1000 / \mathrm{mm}^{3}$ and IgG- $\kappa$ typed M-protein was detected by an analysis of serum electrophoresis. Therefore, it was diagnosed that CMML and MM were simultaneously present. As anemia together with deterioration of renal insufficiency was considered to be MM-related symptoms, treatment by lenalidomide plus dexamethasone (starting doses of $25 \mathrm{mg} /$ day and $20 \mathrm{mg} /$ week, resp.) was started on day 1 of a second admission. On day 7, although both PB-monocytes and serum IgG had significantly decreased, the treatment was discontinued because of disseminated intravascular coagulation, possibly due to tumor lysis syndrome. On day 35 , the patient was complicated with septic shock. Thereafter, his general condition rapidly worsened and he eventually died due to deterioration of CMML.

\section{Discussion}

It has been recognized that MDS or AML (MDS/AML) can develop in patients with MM [3]. The use of anticancer drugs, especially melphalan, has been considered as the main factor for such elevated risk $[4,5]$. Additionally, MM patients have a 2.4-fold to 8.01-fold increased risk of MDS/AML even without such cytotoxic treatment $[6,7]$. On the contrary, simultaneous occurrence of MDS/AML and MM is quite a rare event. In the past, 27 cases of such coexistence of plasma cell dysplasia and myeloid malignancy, including 16 cases with MDS, have been reported [8-20]. Only 2 cases were diagnosed as CMML, while 6 out of 8 AML cases were diagnosed as myelomonocytoid type (AML-M4 or AML-M5 in FAB classification).

It has been demonstrated that myeloma cells express multiple hematopoietic markers, including myelomonocytic antigens [21], and occasionally express biphenotypic features not only of myelomonocytic but also of erythroid, megakaryocytic, and T-lymphoid lineages [22]. It was also reported that $\operatorname{IgG}$ was produced in supernatants from CD14 positive monocytes in such a CMML/MM case. In addition, a rearranged band of IgH gene from $\mathrm{CD} 14+$ peripheral monocytes was identical to that from bone marrow containing plasma cells [8]. According to these findings, it has been speculated that the neoplastic transformation deriving from a common progenitor results in the occurrence of such hybrid hematological disorders. In the present case, myeloma cells 
TABLE 2: The number of PB-monocytes and platelets during 4 years.

\begin{tabular}{|c|c|c|c|c|c|c|}
\hline & $X-4$ years & $X-3$ years & $X-2$ years & $X-1$ years & $X-8$ months & $X$ years \\
\hline $\mathrm{WBC}\left(/ \mathrm{mm}^{3}\right)$ & 3800 & 7900 & 7500 & 6600 & 11000 & 17500 \\
\hline Monocyte (\%) & 28 & 24.5 & 27.5 & 26.7 & 32 & 51.5 \\
\hline Monocytes number $\left(/ \mathrm{mm}^{3}\right)$ & 1064 & 1935 & 2025 & 1780 & 3550 & 8925 \\
\hline Platelet $\left(\times 10^{4} / \mathrm{mm}^{3}\right)$ & 3.6 & 5.3 & 5.6 & 6.9 & 9.2 & 4.5 \\
\hline
\end{tabular}

TABLE 3: Laboratory data on second admission.

\begin{tabular}{|c|c|}
\hline WBC & $17500 / \mathrm{mm}^{3}$ \\
\hline Blast & $0.5 \%$ \\
\hline Myelo & $5.5 \%$ \\
\hline Band & $4.0 \%$ \\
\hline Seg & $32.5 \%$ \\
\hline Mono & $51.5 \%$ \\
\hline Lymph & $4.5 \%$ \\
\hline $\mathrm{RBC}$ & $252 \times 10^{6} / \mathrm{mm}^{3}$ \\
\hline $\mathrm{Hb}$ & $7.7 \mathrm{~g} / \mathrm{dL}$ \\
\hline Platelets & $4.5 \times 10^{4} / \mathrm{mm}^{3}$ \\
\hline $\mathrm{TP}$ & $7.6 \mathrm{~g} / \mathrm{dL}$ \\
\hline Alb & $2.9 \mathrm{mg} / \mathrm{dL}$ \\
\hline BUN & $64.2 \mathrm{mg} / \mathrm{dL}$ \\
\hline $\mathrm{Cr}$ & $2.85 \mathrm{mg} / \mathrm{dL}$ \\
\hline UA & $16.5 \mathrm{mg} / \mathrm{dL}$ \\
\hline $\mathrm{Na}$ & $144 \mathrm{mEq} / \mathrm{L}$ \\
\hline K & $4.7 \mathrm{mEq} / \mathrm{L}$ \\
\hline $\mathrm{Cl}$ & $112 \mathrm{mEq} / \mathrm{L}$ \\
\hline $\mathrm{Ca}$ & $8.1 \mathrm{mEq} / \mathrm{L}$ \\
\hline AST & $12 \mathrm{IU} / \mathrm{L}$ \\
\hline ALT & $6 \mathrm{IU} / \mathrm{L}$ \\
\hline LDH & $248 \mathrm{IU} / \mathrm{L}$ \\
\hline ALP & $106 \mathrm{IU} / \mathrm{L}$ \\
\hline $\operatorname{IgG}$ & $3152 \mathrm{mg} / \mathrm{dL}$ \\
\hline $\operatorname{IgA}$ & $82 \mathrm{mg} / \mathrm{dL}$ \\
\hline $\operatorname{IgM}$ & $29 \mathrm{mg} / \mathrm{dL}$ \\
\hline$\beta-2 \mathrm{MG}$ & $12.9 \mathrm{mg} / \mathrm{L}$ \\
\hline Free light chain $\kappa$ & $2100 \mathrm{mg} / \mathrm{L}$ \\
\hline Free light chain $\lambda$ & $5.8 \mathrm{mg} / \mathrm{L}$ \\
\hline$\kappa / \lambda$ ratio & 362 \\
\hline
\end{tabular}

expressed CD19 antigen, which generally remains in polyclonal but is absent in monoclonal plasma cells and lacked CD138 antigen, which is commonly expressed in myeloma cells [23]. In addition, CD33 antigen, which is expressed in myelomonocytoid but not in plasma cells, was significantly expressed. From these results, it was highly likely that CMML and myeloma cells in the present case originated from these immature, poorly differentiated progenitors or such atypical antigen expression might simply suggest the malignant, but not reactive (benign), properties of the increasing plasma cells, irrespective of the common progenitors.

At disease onset, neither proliferation of plasma cells nor M-peak by analysis of serum protein fractionation was observed. In contrast, the number of PB-monocytes gradually increased and finally exceeded $1000 / \mathrm{mm}^{3}$ during the 4-year period of prednisolone plus eltrombopag treatment. Therefore, it was concluded that CMML existed as an underlying disorder when the patient was firstly diagnosed with ITP, and the present case is the first report of myeloid malignancy proceeding the occurrence of MM.

It has been widely recognized that MDS with CMML is complicated with various types of autoimmune disorders, such as Sweet's disease $[2,24]$. It has also been reported that immune-mediated thrombocytopenia can occur in CMML $[2,24]$. Hadjadj et al. reported that ITP occurred in the early stage of CMML with no further progression of the disorder. In their report, a favorable response to treatment, including corticosteroid or TPO-R agonist, was obtained. Ineffective platelet production secondary to disordered maturation or proliferation of megakaryocytes has been considered as the other main mechanism of thrombocytopenia in MDS [25]. Eltrombopag has been shown to be useful to treat thrombocytopenia in MDS patients [26]. Platelet counts were improved or remained stable in 9 out of 12 cases, despite azacitidine treatment [27]. A meta-analysis study also demonstrated that romiplostim, another TPO-R agonist, significantly decreases the bleeding or platelet transfusion rate [28]. In the present case, eltrombopag was shown to be effective in maintaining platelet counts for as long as 4 years before diagnosis of CMML/MM.

The safety of long-term treatment by TPO-R agonist has recently been reported and only 2 patients suffered from lymphoid malignancies of diffuse large B-cell and Hodgkin lymphoma [29]. The relative risk of AML progression with romiplostin was 1.36; however, this result was judged as having a high risk of bias [28]. In addition, eltrombopag inhibits proliferation of leukemic cells through a TPO-R independent mechanism in vitro $[27,30,31]$. From these reports, it was concluded that eltrombopag was not involved in either the progression of CMML or the development of MM.

Lenalidomide, an immunomodulatory drug, is widely known as one of the key drugs for initial treatment of MM and also has been approved for low or low-intermediate risk MDS with del(5q) $[32,33]$. The drug is also effective, even if to a lesser extent in non-del(5q) MDS. In an MDS-002 trial, the drug demonstrated transfusion independence in one quarter of MDS patients not harboring del(5q) [34]. It also shows a clinical response in CMML patients $(25 \%$ of overall response), when combined with metronomic melphalan through an antiangiogenic effect [35]. We selected this drug to treat both MM and CMML. However, only a temporal improvement of these disorders was obtained, 



FIGURE 2: Flow cytometry of bone marrow. CD38 positive cells were positively stained with CD19, CD33, and $\kappa$ antigens and negatively with CD138, CD20, and $\lambda$ antigens. 
and eventually, the treatment was discontinued because of decreased performance status due to complications of the severely infectious disease.

Other effective treatments with azacitidine, an analog of pyrimidine nucleoside, have been used in various myeloid malignancies, including CMML [36]. Clinical trials with combination therapy of lenalidomide and azacitidine have been reported. In one study, an overall response rate of $72 \%$, including $44 \%$ with complete response, was obtained [37]. Such combination therapy might be a promising option as long as the general conditions of the patient were favorable enough to continue the chemotherapy.

\section{Competing Interests}

Authors have no conflict of interests.

\section{References}

[1] N. Cooper and J. Bussel, "The pathogenesis of immune thrombocytopaenic purpura," British Journal of Haematology, vol. 133, no. 4, pp. 364-374, 2006.

[2] M. W. Saif, J. L. Hopkins, and S. D. Gore, "Autoimmune phenomena in patients with myelodysplastic syndromes and chronic myelomonocytic leukemia," Leukemia \& Lymphoma, vol. 43, no. 11, pp. 2083-2092, 2002.

[3] R. A. Kyle, R. V. Pierre, and E. D. Bayrd, "Multiple myeloma and acute myelomonocytic leukemia," The New England Journal of Medicine, vol. 283, no. 21, pp. 1121-1125, 1970.

[4] R. Govindarajan, S. Jagannath, J. T. Flick et al., "Preceding standard therapy is the likely cause of MDS after autotransplants for multiple myeloma," British Journal of Haematology, vol. 95, no. 2, pp. 349-353, 1996.

[5] J. Cuzick, S. Erskine, D. Edelman, and D. A. G. Galton, "A comparison of the incidence of the myelodysplastic syndrome and acute myeloid leukaemia following melphalan and cyclophosphamide treatment for myelomatosis. A report to the Medical Research Council's working party on leukaemia in adults," British Journal of Cancer, vol. 55, no. 5, pp. 523-529, 1987.

[6] L. E. Roeker, D. R. Larson, R. A. Kyle, S. Kumar, A. Dispenzieri, and S. V. Rajkumar, "Risk of acute leukemia and myelodysplastic syndromes in patients with monoclonal gammopathy of undetermined significance (MGUS): a population-based study of 17315 patients," Leukemia, vol. 27, no. 6, pp. 1391-1393, 2013.

[7] S. Mailankody, R. M. Pfeiffer, S. Y. Kristinsson et al., "Risk of acute myeloid leukemia and myelodysplastic syndromes after multiple myeloma and its precursor disease (MGUS)," Blood, vol. 118, no. 15, pp. 4086-4092, 2011.

[8] K. Akashi, M. Harada, T. Shibuya et al., "Simultaneous occurrence of myelomonocytic leukemia and multiple myeloma: involvement of common leukemic progenitors and their developmental abnormality of 'lineage infidelity"' Journal of Cellular Physiology, vol. 148, no. 3, pp. 446-456, 1991.

[9] T. Economopoulos, V. Pappa, A. Panani et al., "Myelopathies during the course of multiple myeloma," Haematologica, vol. 76, no. 4, pp. 289-292, 1991.

[10] R. Rios Tamayo, F. Sole, and F. Gascon, "Simultaneous occurrence of the 5q-syndrome and multiple myeloma," Clinical and Laboratory Haematology, vol. 22, no. 1, pp. 49-51, 2000.
[11] G. A. Kastanas, C. A. Papaioannou, and H. A. Nathena, "Multiple myeloma and acute leukemia," Acta Haematologica, vol. 62, no. 2, pp. 78-80, 1979.

[12] I. Raz and A. Polliack, "Coexistence of myelomonocytic leukemia and monoclonal gammopathy or myeloma. Simultaneous presentation in three patients," Cancer, vol. 53, no. 1, pp. 83-85, 1984.

[13] A. C. Parker, "A case of acute myelomonocytic leukaemia associated with myelomatosis," Scandinavian Journal of Haematology, vol. 11, no. 4, pp. 257-260, 1973.

[14] B. Cleary, R. A. Binder, A. N. Kales, and B. J. Veltri, "Simultaneous presentation of acute myelomonocytic leukemia and multiple myeloma," Cancer, vol. 41, no. 4, pp. 1381-1386, 1978.

[15] L. Taddeini and W. Schrader, "Concomitant myelomonocytic leukemia and multiple myeloma," Minnesota Medicine, vol. 55, no. 5, pp. 446-448, 1972.

[16] L. Parapia, C. R. Abbott, G. Masters, and B. E. Roberts, "Simultaneous presentation of acute myelomonocytic leukaemia and multiple myeloma," Acta Haematologica, vol. 68, no. 2, pp. 153$156,1982$.

[17] K. Shibata, Y. Shimamoto, S. Nakazato, M. Matsuzaki, and J. Tadano, "Refractory anaemia with ringed sideroblasts concurrent with multiple myeloma-a brief review of the recent literature," Haematologia, vol. 28, no. 4, pp. 199-205, 1997.

[18] G. J. Mufti, T. J. Hamblin, G. P. Clein, and C. Race, "Coexistent myelodysplasia and plasma cell neoplasia," British Journal of Haematology, vol. 54, no. 1, pp. 91-96, 1983.

[19] J. A. Copplestone, G. J. Mufti, T. J. Hamblin, and D. G. Oscier, "Immunological abnormalities in myelodysplastic syndromes. II. Coexistent lymphoid or plasma cell neoplasms: a report of 20 cases unrelated to chemotherapy," British Journal of Haematology, vol. 63, no. 1, pp. 149-159, 1986.

[20] L. Annino, P. Martino, P. Barsotti, P. Serra, V. Marinozzi, and F. Mandelli, "Multiple myeloma and acute myelomonocytic leukemia: simultaneous occurrence without previous chemotherapy," Acta Haematologica, vol. 64, no. 4, pp. 195-200, 1980.

[21] T. M. Grogan, B. G. M. Durie, C. M. Spier, L. Richter, and E. Vela, "Myelomonocytic antigen positive multiple myeloma," Blood, vol. 73, no. 3, pp. 763-769, 1989.

[22] J. Epstein, H. Xiao, and X.-Y. He, "Markers of multiple hematopoietic-cell lineages in multiple myeloma," The New England Journal of Medicine, vol. 322, no. 10, pp. 664-668, 1990.

[23] F. G. Rosado, W. G. Morice, R. He, M. T. Howard, M. Timm, and E. D. Mcphail, "Immunophenotypic features by multiparameter flow cytometry can help distinguish low grade B-cell lymphomas with plasmacytic differentiation from plasma cell proliferative disorders with an unrelated clonal B-cell process," British Journal of Haematology, vol. 169, no. 3, pp. 368-376, 2015.

[24] J. Hadjadj, M. Michel, M.-P. Chauveheid, B. Godeau, T. Papo, and K. Sacre, "Immune thrombocytopenia in chronic myelomonocytic leukemia," European Journal of Haematology, vol. 93, no. 6, pp. 521-526, 2014.

[25] U. Kalina, W.-K. Hofmann, S. Koschmieder et al., "Alteration of c-mpl-mediated signal transduction in $\mathrm{CD} 34^{+}$cells from patients with myelodysplastic syndromes," Experimental Hematology, vol. 28, no. 10, pp. 1158-1163, 2000.

[26] C. K. Brierley and D. P. Steensma, "Thrombopoiesis-stimulating agents and myelodysplastic syndromes," British Journal of Haematology, vol. 169, no. 3, pp. 309-323, 2015. 
[27] T. Svensson, O. Chowdhury, H. Garelius et al., "A pilot phase I dose finding safety study of the thrombopoietin-receptor agonist, eltrombopag, in patients with myelodysplastic syndrome treated with azacitidine," European Journal of Haematology, vol. 93, no. 5, pp. 439-445, 2014.

[28] A. Prica, M. Sholzberg, and R. Buckstein, "Safety and efficacy of thrombopoietin-receptor agonists in myelodysplastic syndromes: a systematic review and meta-analysis of randomized controlled trials," British Journal of Haematology, vol. 167, no. 5, pp. 626-638, 2014.

[29] M. N. Saleh, J. B. Bussel, G. Cheng et al., "Safety and efficacy of eltrombopag for treatment of chronic immune thrombocytopenia: results of the long-term, open-label EXTEND study," Blood, vol. 121, no. 3, pp. 537-545, 2013.

[30] B. Will, M. Kawahara, J. P. Luciano et al., "Effect of the nonpeptide thrombopoietin receptor agonist Eltrombopag on bone marrow cells from patients with acute myeloid leukemia and myelodysplastic syndrome," Blood, vol.114, no. 18, pp. 38993908, 2009.

[31] C. L. Erickson-Miller, J. Kirchner, M. Aivado, R. May, P. Payne, and A. Chadderton, "Reduced proliferation of non-megakaryocytic acute myelogenous leukemia and other leukemia and lymphoma cell lines in response to eltrombopag," Leukemia Research, vol. 34, no. 9, pp. 1224-1231, 2010.

[32] H. Harada, M. Watanabe, K. Suzuki et al., "Lenalidomide is active in Japanese patients with symptomatic anemia in low- or intermediate-1 risk myelodysplastic syndromes with a deletion 5q abnormality," International Journal of Hematology, vol. 90, no. 3, pp. 353-360, 2009.

[33] P. Fenaux, A. Giagounidis, D. Selleslag et al., "A randomized phase 3 study of lenalidomide versus placebo in RBC transfusion-dependent patients with Low-/Intermediate-1-risk myelodysplastic syndromes with del5q," Blood, vol. 118, no. 14, pp. 3765-3776, 2011.

[34] A. Raza, J. A. Reeves, E. J. Feldman et al., "Phase 2 study of lenalidomide in transfusion-dependent, low-risk, and intermediate-1 risk myelodysplastic syndromes with karyotypes other than deletion 5q," Blood, vol. 111, no. 1, pp. 86-93, 2008.

[35] R. Buckstein, R. Kerbel, M. Cheung et al., "Lenalidomide and metronomic melphalan for CMML and higher risk MDS: a phase 2 clinical study with biomarkers of angiogenesis," Leukemia Research, vol. 38, no. 7, pp. 756-763, 2014.

[36] L. Adès, M. A. Sekeres, A. Wolfromm et al., "Predictive factors of response and survival among chronic myelomonocytic leukemia patients treated with azacitidine," Leukemia Research, vol. 37, no. 6, pp. 609-613, 2013.

[37] M. A. Sekeres, R. V. Tiu, R. Komrokji et al., "Phase 2 study of the lenalidomide and azacitidine combination in patients with higher-risk myelodysplastic syndromes," Blood, vol. 120, no. 25, pp. 4945-4951, 2012. 


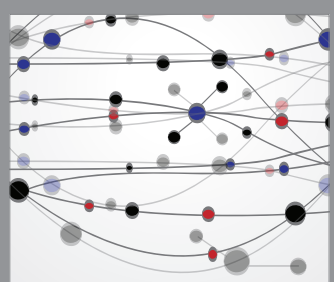

The Scientific World Journal
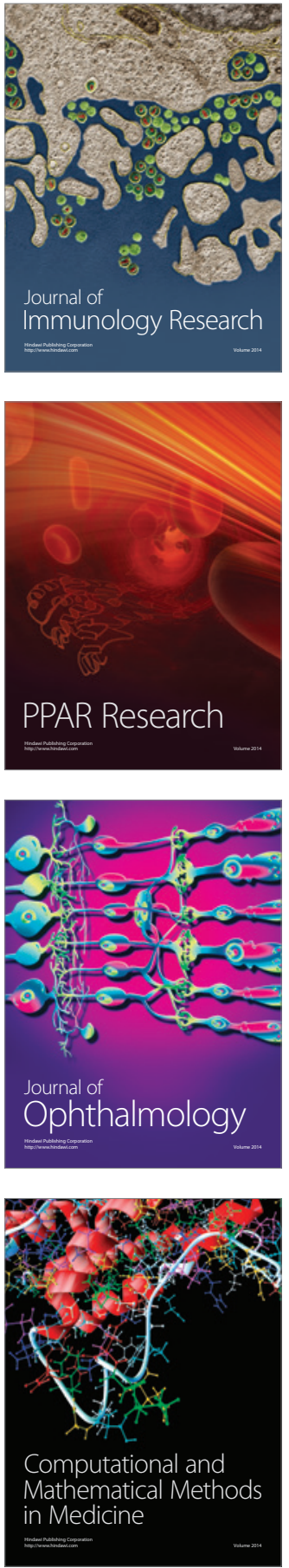

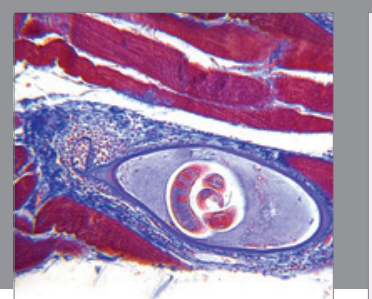

Gastroenterology Research and Practice

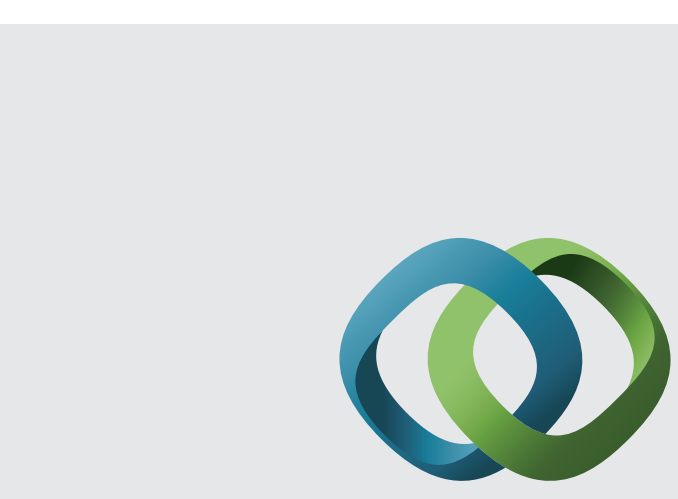

\section{Hindawi}

Submit your manuscripts at

http://www.hindawi.com
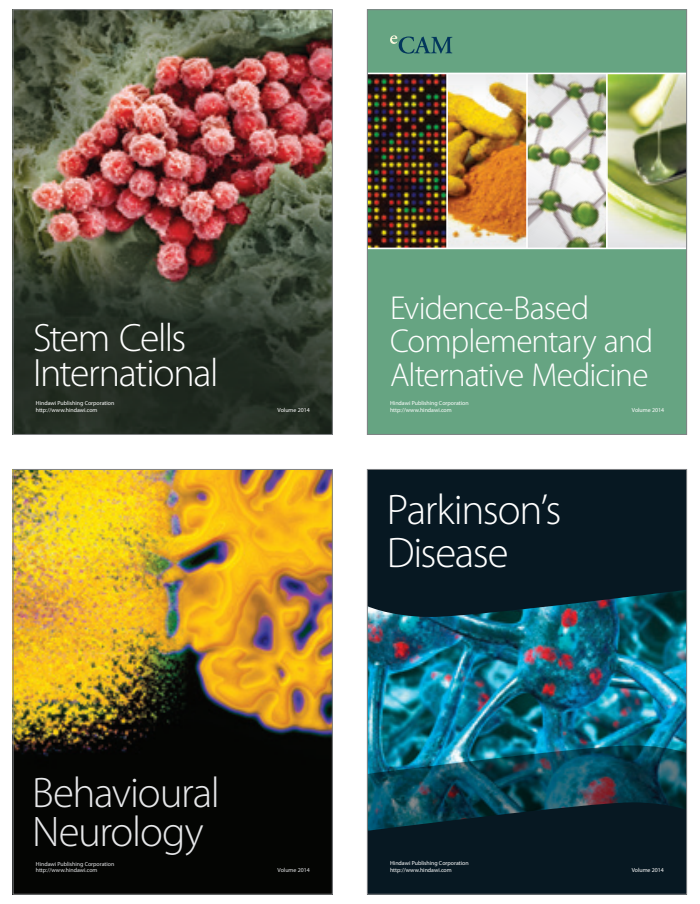
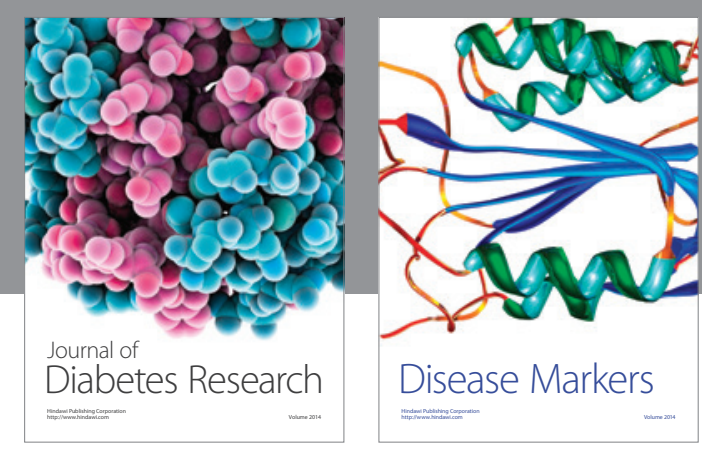

Disease Markers
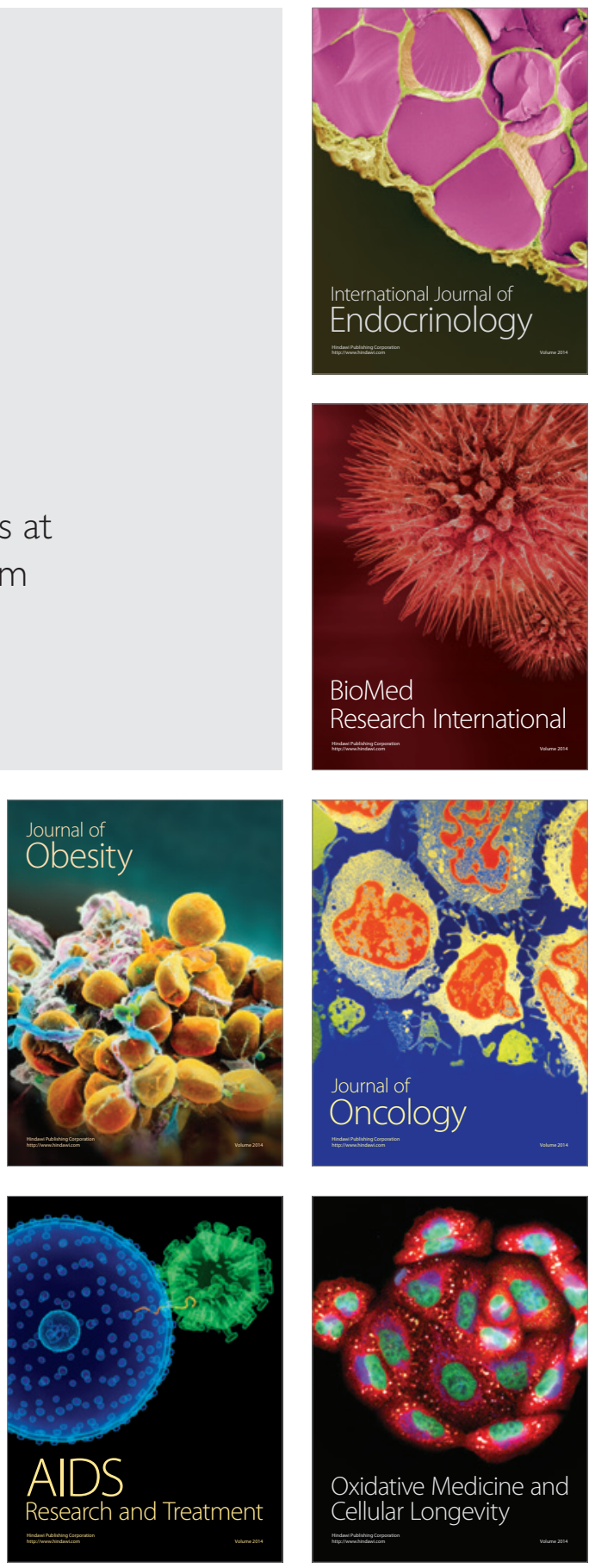